\title{
Capacités de morphogenèse in vitro de divers clones de lavandes et lavandins: observations préliminaires sur la valeur agronomique des vitroplants
}

\author{
C Chambon ${ }^{1,2}$, A Poupet $^{1}$, D Beck ${ }^{1}$, B Bettachini ${ }^{1}$, J Touche ${ }^{2}$ \\ ${ }^{\prime}$ INRA, station de botanique et pathologie végétale, villa Thuret, 62 bd du cap, BP 2078, 06606 Antibes Cedex; \\ ${ }^{2}$ CEAMS, 40, rue CA Helvetius BP 151, 84140 Montfavet, France
}

(Reçu le 26 août 1991; accepté le 10 janvier 1992)

\begin{abstract}
Résumé - Nous avons comparé les aptitudes morphogénétiques de clones commerciaux de lavandins (Abrial, Grosso, Super) et de lavandes (aspic et Maillette) cultivés in vitro. Des milieux de culture adaptés au développement des apex méristématiques, à la multiplication et à l'enracinement des pousses feuillées de clones de lavandin et de la lavande aspic ont été définis. Des exigences spécifiques des clones sont toutefois apparues, en particulier vis-à-vis des régulateurs de croissance. En revanche, il n'a pas été possible d'entretenir la multiplication in vitro de la lavande Maillette dans les conditions expérimentales utilisées. L'intérêt de la culture in vitro pour la production d'un matériel végétal conforme et présentant de bonnes performances agronomiques, a été démontré par l'observation du comportement au champ de plusieurs dizaines de milliers d'individus. L'utilisation des résultats obtenus pourrait constituer une alternative intéressante face au problème du "dépérissement " de ces espèces si une cause pathologique de ce syndrome était confirmée.
\end{abstract}

Lavandula / micropropagation / conformité au type / analyse chimique

Summary - In vitro morphogenetic potential of various lavandin and lavender clones: preliminary observations on the agronomic value of the vitroplants. Lavenders and lavandins (sterile and spontaneous interspecific hybrids between fine lavender, Lavandula angustifolia Mill, and lavender aspic, Lavandula latifolia Will) are of significant importance for dry areas in South East of France. Nowadays, the expansion of production is limited by further increase in decline phenomena hypothetically caused, in part, by vascular pathogens. We reported previously on the regeneration of lavandin Abrial by meristem tip culture, and we now present a comparison of the morphogenetic potential of some commercial cultivars of in vitro cultivated lavandins (Abrial, Grosso and Super) and lavenders (aspic and Maillette). We have developed specific media suited for shoot tip growth, multiplication by axillary budding, and rooting. These media allow a good propagation of the lavandin clones studied (Abrial, Grosso and Super) and the aspic lavender. Specific requirements for the indolyl butyric acid (IBA) growth regulator have been the determined for proper multiplication of the lavandin Abrial. However, using these various media, it was not possible to maintain fast-growing lavender Maillette strains. In addition, once planted in soil, more than 45000 lavandin vitroplants produced by this method showed very good quality characteristics and proved to be true to type with respect to their essential oil composition. These data show that these experimental conditions could provide a partial answer to the decline phenomenon observed in the lavandins and lavenders. 


\section{INTRODUCTION}

Les Labiées constituent une famille botanique importante au plan industriel, de par la richesse de certains genres en huiles essentielles odorantes, particulièrement recherchées par l'industrie des parfums, dans laquelle le groupe lavandes-lavandins joue un rôle économique et social notable pour certaines zones sèches du Sud-Est de la France. Notre pays est en effet, le premier producteur mondial d'essences de lavandin, hybride entre la lavande fine (Lavandula angustifolia Mill) et la lavande aspic (Lavandula latifolia Will).

Cependant depuis une dizaine d'années, on observe une réduction notable des plantations de lavandes (5000 et 3000 ha respectivement en 1980 et 1988) et de lavandins (17 000 et 12000 ha pour les mêmes dates) (Chailan, 1989).

Le déclin relatif de ces productions, en dépit de la persistance de la demande du marché trouve son origine dans certains paramètres techniques, en particulier, la diminution de la longévité et de la productivité des plantations, imputable à l'extension des phénomènes de "dépérissements". Décrits de longue date (Caire, 1970), ceux-ci ont une étiologie complexe, pouvant être attribuée à des facteurs multiples, agissant isolément ou en synergie: qualité du matériel végétal multiplié végétativement depuis longtemps, modifications des techniques culturales, conséquences d'accidents climatiques, intervention potentielle d'agents pathogènes de types mycoplasmes (Cousin et al, 1969).

Dans cette dernière hypothèse, Maia et al, ont développé en 1973, une méthode de régénération par culture d'apex méristématiques du lavandin Abrial, particulièrement sensible au dépérissement.

Depuis cette date, un certain nombre de travaux ont été consacrés, d'une part, à la multiplication végétative conforme in vitro des lavandins Grosso (Chambon et al, 1987; Panizza et Tognoni (1988); Panizza et al (1988) Abrial et Super (Chambon et al, 1987) et de la lavande (Oliphant, 1987), et d'autre part, à la régénération de bourgeons adventifs à partir de divers tissus de lavande aspic, lavande fine, lavande stoechas et lavandins (Quazi, 1980; Webb et al, 1984; Chambon et al, 1988; Calvo et Segura, 1988, 1989).

Le présent article, rapporte des résultats expérimentaux obtenus pendant plusieurs an- nées et concernant les capacités de morphogenèse in vitro de divers clones commerciaux, de lavandes et de lavandins, et les performances agronomiques des individus obtenus.

L'intérêt de ce travail réside dans le fait que l'existence de méthodes de régénération et de multiplication conforme accélérée, adaptées à chaque cas, pourrait constituer une solution, au moins partielle, au problème des "dépérissements" des plantations, dans l'hypothèse d'une cause pathologique de ce phénomène.

\section{MATÉRIELS ET MÉTHODES}

\section{Matériel végétal}

Nous avons étudié le comportement des 3 clones de lavandins les plus cultivés (Abrial, Grosso, Super), d'un clone de lavande fine (Maillette) et d'un clone de lavande aspic. Les plants utilisés proviennent d'une collection entretenue en serre à la station de pathologie végétale INRA d'Antibes depuis plus de 10 ans (Maia, 1981).

\section{Culture in vitro}

\section{Mise en culture d'apex méristématiques}

Nous avons utilisé exclusivement comme explant initial des extrémités apicales d'une longueur approximative de $200 \mu \mathrm{m}$, comportant 2 ébauches foliaires. Prélevées sans désinfection préalable sous loupe binoculaire, elles sont placées dans des tubes à hémolyse contenant $2 \mathrm{ml}$ d'un milieu de culture favorisant leur élongation. Sa composition définie antérieurement au laboratoire (Maia et al, 1973) est indiquée dans le tableau I (milieu 1). Le $\mathrm{pH}$ est ajusté à 5,8 avec $\mathrm{KOH} 1 \mathrm{~mol} \cdot \mathrm{I}^{-1}$ avant stérilisation par autoclavage à $110^{\circ} \mathrm{C}$ pendant $20 \mathrm{~min}$.

\section{Multiplication des pousses feuillées et enracinement}

Les pousses feuillées obtenues après le développement des apex méristématiques, sont transférées sur 2 milieux différents (tableau I; milieux 2, 3) à raison de $10 \mathrm{ml}$ de milieu par tube de $150 \times 25 \mathrm{~mm}$, obturé par un bouchon en polycarbonate Afiplastex. 
Tous les individus obtenus, à l'issue des cycles de multiplication, sont transférés sur un même milieu de culture favorable à leur enracinement (tableau I, milieu 4).

\section{Conditions de culture}

Les conditions d'environnement, identiques pour toutes les étapes sont les suivantes: température: $23 \pm 1^{\circ} \mathrm{C}$; durée d'éclairement: $16 \mathrm{~h}$; intensité d'éclairement: $15 \mathrm{~W} / \mathrm{m}^{2}$, fournis par des tubes fluorescents Mazda Incandia Prestiflux.

\section{Acclimatation des plantes}

Quant les individus présentent un enracinement satisfaisant, caractérisé par un équilibre correct entre les systèmes caulinaire et radiculaire, ils sont extraits des tubes de culture et après rinçage des racines, sont plantés en serre, dans un mélange sable-terreau, en conditions d'humidité saturante pendant $15 \mathrm{j}$. Après un séjour de 6 semaines en serre, ils sont aptes à être transplantés au champ.

\section{Notations et analyses statistiques}

Afin de comparer le comportement in vitro des 5 clones de lavandes et lavandins, plusieurs séries de notations ont été effectuées sur des cultures "stabilisées" (voir Résultats). Elles ont été réalisées pendant 4 subcultures successives, au stade multiplication, au cours de 4 essais d'enracinement et lors d'un essai d'acclimatation.

Réalisées après $30 \mathrm{j}$ de culture in vitro, elles ont pris en compte les critères suivants:

\section{Stade multiplication \\ Taux de multiplication, c'est-à-dire le nombre de pousses développées, d'une taille supérieure à $8 \mathrm{~mm}$, utilisables lors de chaque subculture; lon- gueur de la pousse principale; poids de matière fraîche de la souche; pourcentages d'explants via- bles et le cas échéant, d'individus enracinés; fré- quence des cas de turgescence exagérée des tissus ("vitrification").}

\section{Stade enracinement}

Longueur de la tige; nombre de racines; pourcentage d'explants enracinés; longueur de la racine

Tableau I. Composition des milieux de culture utilisés pour le développement des apex méristématiques (milieu $n^{\circ} 1$ ), la multiplication (milieux $n^{\circ} 2$ et 3 ) et l'enracinement (milieu $n^{\circ} 4$ ) des divers clones de lavandes et lavandins. Les quantités sont exprimées en $\mathrm{mg} \cdot \mathrm{l}^{-1}$ de milieu final. Le pH est ajusté à 5,8 . * Les signes $1 / 1,1 / 2$ indiquent que les éléments sont utilisés à la concentration normale ou réduite de moitié. MS 400 = Minéraux de Murashige et Skoog (1962) dans lesquels $\mathrm{NH}_{4} \mathrm{NO}_{3}$ est réduit à $400 \mathrm{mg} / \mathrm{l}$.

\begin{tabular}{|c|c|c|c|c|}
\hline $\begin{array}{l}\text { Composants } \\
\text { des milieux de culture }\end{array}$ & Milieu $n^{0} 1$ & Milieu $n^{0} 2$ & Milieu $n^{0} 3$ & Milieu $n^{\circ} 4$ \\
\hline $\begin{array}{l}\text { Macroéléments de Tulecke } \\
\text { et Sehgal (1963) }\end{array}$ & $1 / 1^{*}$ & $1 / 1^{*}$ & $1 / 1^{*}$ & \\
\hline Macroéléments MS 400 & & & & $1 / 2^{*}$ \\
\hline Microéléments MS & $1 / 1^{*}$ & $1 / 1^{*}$ & $1 / 1^{*}$ & $1 / 1^{*}$ \\
\hline Fe EDTA & 27 & 27 & 27 & 13,5 \\
\hline Vitamines $B$ & 1 & 1 & 1 & 0,5 \\
\hline Biotine & & & & 0,5 \\
\hline Acide ascorbique & 50 & 50 & 50 & 25 \\
\hline Myo-inositol & 100 & 100 & 100 & 50 \\
\hline Glutamine & 200 & & & \\
\hline Glycocolle & 200 & & & \\
\hline Sulfate-hydroxy-quinoléine & 0,5 & & & \\
\hline $\mathrm{GA}_{3}$ & 1 & & & \\
\hline AIA & & & & 0,4 \\
\hline AIB & 0,1 & & 0,05 & \\
\hline Kinétine & 1 & & & \\
\hline$N_{6}$ benzyladénine & & 0,1 & 0,1 & \\
\hline Glucose & 30000 & & & 15000 \\
\hline Saccharose & & 15000 & 15000 & \\
\hline Agar & 7000 & 8000 & 8000 & 7000 \\
\hline
\end{tabular}


la plus développée; pourcentage d'individus viables.

Dans les 2 stades précédents, pour chaque subculture ou essai, les notations ont concerné 24 individus de chaque clone.

\section{Stade acclimatation}

La longueur de la pousse principale a été déterminée après 10 semaines d'acclimatation, dans des lots de 10 individus de chacun des 5 clones étudiés.

Les analyses de variance de tous les résultats obtenus ont été réalisées grâce à l'usage de logiciels informatiques Genstat et Modli.

\section{Comportement au champ}

En 1986, un essai de comportement de 1000 vitroplants du clone Grosso comparés à des individus du même clone obtenus par bouturage traditionnel ( 600 boutures ligneuses) a été implanté dans une zone de production du lavandin.

Sur ce lot, 3 campagnes de notations et de mesures, réalisées en 1987, 1988, 1989 ont concerné les rendements respectifs en matière fraîche et en huile essentielle après distillation. En 1987, les essences obtenues par entraînement à la vapeur d'eau ont également été analysées en chromatographie en phase gazeuse, selon les normes AFNOR (1989).

Par ailleurs, au cours des campagnes successives 1986, 1987 et 1988, 14000 vitroplants du clone Grosso, 10000 du clone Abrial et $500 \mathrm{du}$ clone Super ont également été implantés.

\section{RÉSULTATS}

\section{Développement des apex méristématiques}

Hormis le cas de la lavande aspic, $70-80 \%$ des apex méristématiques issus des autres clones mis en culture se développent de façon satisfaisante: en 4-6 semaines, on obtient des pousses feuillées normalement chlorophylliennes, sans cal basal, de $10-15 \mathrm{~mm}$ de longueur, comportant au moins une paire de feuilles. De faibles variations de leur vitesse d'élongation ont pu néanmoins être observées en fonction de l'époque de prélèvement des extrémités apicales, le printemps apparaissant comme la période la plus favorable.

$\mathrm{Ce}$ dernier facteur semble déterminant dans le cas de la lavande aspic: seuls les mé- ristèmes prélevés au moment de la reprise de végétation des pieds mères, c'est-à-dire au printemps, manifestent un excellent développement, avec un pourcentage de réussite supérieur à $90 \%$.

\section{Comportement des divers clones au stade multiplication}

\section{Essais préliminaires correspondant à la phase de «stabilisation" des cultures}

Des pousses feuillées issues d'apex des divers clones de lavandes et lavandins ont été transférées, à un stade de développement comparable, sur l'un ou l'autre des 2 milieux de multiplication. Les observations qualitatives suivantes ont été réalisées pendant 6 subcultures:

- sur le milieu 2 (tableau I), au cours des repiquages successifs, l'aptitude à la multiplication du clone Abrial est progressivement réduite et la fréquence de la présence de cal accrue. En revanche, sur le même milieu, il est possible d'assurer, pendant un nombre élevé de subcultures, la multiplication des clones de lavandins Grosso et Super (fig 1), ce dernier présentant toutefois, un aspect plus grêle;

- à l'inverse, le milieu 3 (tableau I), se montre approprié à l'amplification des souches du clone Abrial, alors que les clones Super et Grosso manifestent à terme un jaunissement et une nécrose, accélérés dans le cas du clone Super. Sur le même milieu, les comportements de la lavande aspic et Maillette apparaissent plus tranchés (fig 2). Les pousses de lavande aspic s'allongent rapidement, avec des entre-nœuds longs, sans tendance à une ramification basitone et présentent le plus souvent une pousse unique. Dans le cas de la Maillette, après une période d'exubérance initiale lors de la mise en culture, les explants se développent de moins en moins au cours des repiquages successifs, et présentent des entre-nœuds très courts.

Dans la suite, nous entendrons par "stabilisation " des cultures, le comportement apparemment invariant d'un clone soumis, lors de chaque subculture à une interaction fixe: milieu de culture-conditions d'environnement, portant sur l'aspect, la structure, une vitesse 


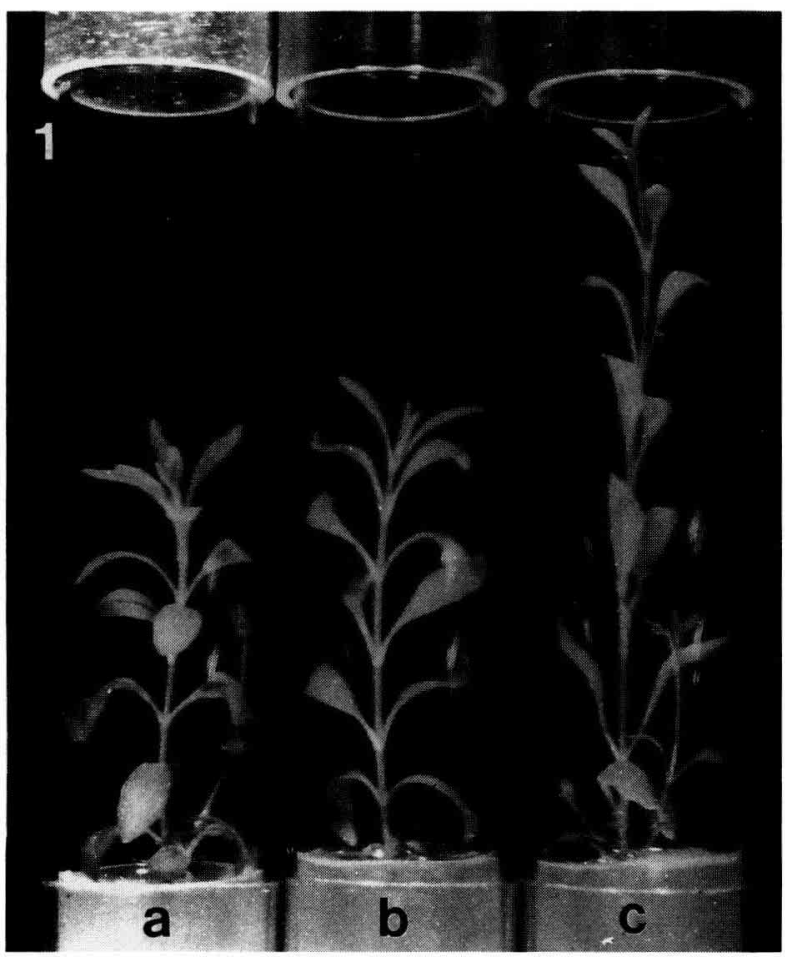

Fig 1. Comportement comparé des 3 clones de lavandins au stade multiplication in vitro, après $30 j$ de culture. ( $a=$ Abrial, multiplié sur milieu $3 ; b=$ Grosso et $c=$ Super, multipliés sur milieu 2).

d'élongation identique des pousses, et un taux de multiplication constant.

\section{Notations effectués sur les cultures « stabilisées »}

À la suite des observations précédentes, ont été retenues pour la phase de multiplication, les associations milieu-clone suivantes:

- milieu 2, clones Grosso et Super;

- milieu 3, clones Abrial, lavande aspic et Maillette.

En utilisant ces couples milieu-clone pendant 4 subcultures et en mesurant le taux de multiplication, le poids de matière fraîche (PMF) et la longueur de la pousse principale, des différences significatives dans les comportements des clones ont pu être mises en évidence (tableau II):

- la supériorité du comportement du clone Abrial apparaît nettement au niveau du taux de multiplication et des poids de matière fraîche;

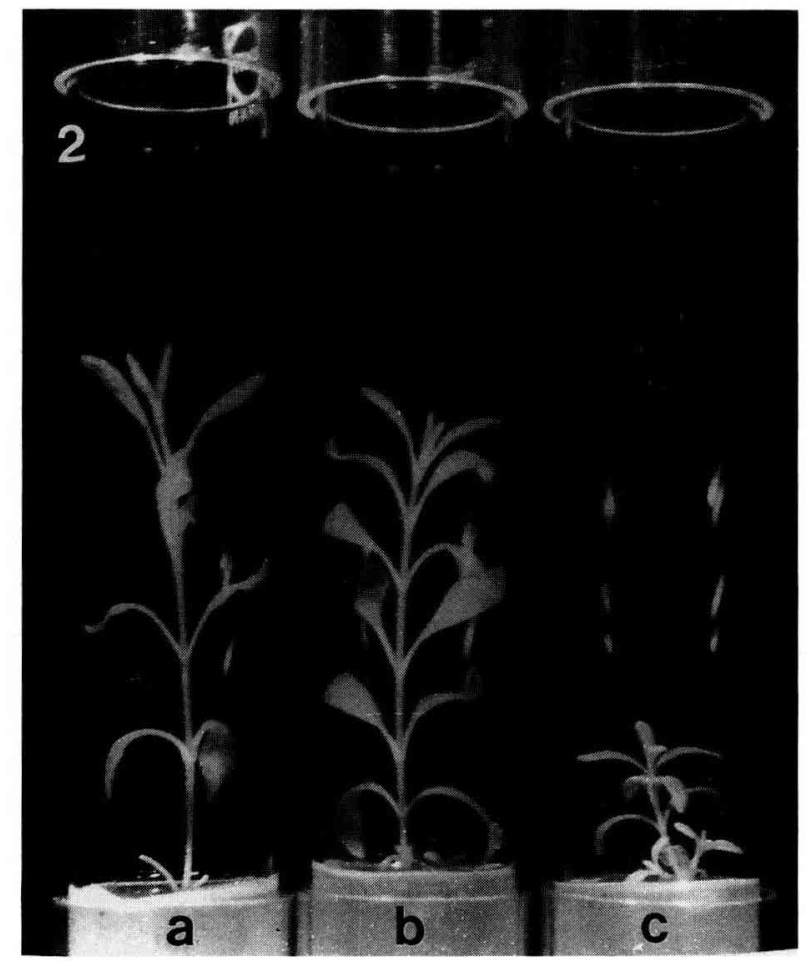

Fig 2. Comportement comparé de la lavande aspic (a), du lavandin Grosso (b) et de la lavande Maillette (c), au stade multiplication in vitro, après $30 \mathrm{j}$ de culture. (a et c, multipliés sur le milieu 3, b multiplié sur le milieu 2).

- l'allongement le plus important, associé au taux de multiplication le plus faible est observé chez le clone de lavande aspic;

- la lavande Maillette a le développement le plus lent.

Pour ce qui concerne le taux de multiplication sensu stricto, inférieur à 2 dans tous les cas, il peut apparaître faible: il ne prend toutefois en compte que le nombre de pousses latérales suffisamment développées et exclut l'usage potentiel des boutures nodales. L'utilisation conjointe de ces dernières et des pousses axillaires assurerait un taux de multiplication mensuel au moins égal à 4 .

\section{Comportement des divers clones au cours des phases de rhizogenèse et d'acclimatation}

Globalement, le comportement des clones de lavandins et de la lavande aspic apparaît homogène: à l'inverse, l'analyse statistique des résultats démontre le caractère significativement différent de la lavande Maillette (tableau II). 
Dans le cas des lavandins et de la lavande aspic, le milieu de culture unique utilisé permet, après $30 \mathrm{j}$ de culture, un enracinement supérieur à $93 \%$ et une survie au moins égale à $71 \%$. L'émission des méristèmes radiculaires apparaît après environ $10 \mathrm{j}$ et conduit au développement de 5-6 racines ramifiées sans cal basal.

Pour la lavande aspic et le lavandin Super, les résultats apparaissent qualitativement supérieurs, les chiffres respectifs étant de 97 et $85 \%$. Ce dernier résultat indique une aptitude plus élevée à l'enracinement de ces clones et suggère une possible simplification du schéma de micropropagation. Ainsi, un simple bouturage de nœuds, remplacerait avantageusement le recours à la séquence des 2 milieux successifs, principalement dans le cas de la lavande aspic pour laquelle l'induction du développement des bourgeons axillaires par le milieu de multiplication apparaît sans effet.

II est plus aléatoire de porter un jugement fondé sur la lavande Maillette, compte tenu du comportement marginal et peu satisfaisant de ce clone dans les conditions expérimentales retenues: dans ce cas, les travaux restent à poursuivre au stade multiplication, avant de chercher à améliorer la phase d'enracinement.

Quant à la phase d'acclimatation en serre, le développement des systèmes aériens des lavandins est homogène et nettement supérieur à celui de leurs parents respectifs théoriques, lavande aspic et lavande fine, ce qui peut évoquer une vigueur hybride (tableau II).

Les nombreuses expérimentations conduites au stade acclimatation en serre, associées à 3 années de production pré-industrielle ont permis de définir un stade précis de développement assurant un pourcentage de reprise ultérieure voisin de $100 \%$ : les individus doivent être d'une taille au moins égale à $20 \mathrm{~mm}$, et présenter plusieurs racines ramifiées d'environ $10 \mathrm{~mm}$. Ce stade s'obtient généralement après le séjour des pousses pendant 3 semaines sur le milieu d'enracinement.

Par ailleurs, il est apparu, dans le cas des dizaines de milliers de vitroplants produits, qu'une durée d'acclimatation n'excédant pas 6 semaines est appropriée pour favoriser la reprise ultérieure au champ. Certains essais ont en effet démontré qu'une période plus longue entraînait un enroulement excessif des racines, néfaste en cas de "stress " mécanique ou climatique.

\section{Résultats obtenus après plantation au champ}

En ce qui concerne les lavandins, les méthodologies mises au point ont permis la production et l'acclimatation au champ, durant 3 ans, de 15000 plants du clone Grosso, 10000 du clone Abrial et 500 du clone Super. Ces individus ont été implantés dans le Nord-Est du

Tableau II. Comportements comparés des 5 clones de lavandes et lavandins aux stades multiplication (1), enracinement (2) et acclimatation (3). Valeurs moyennes calculées sur 4 subcultures (1), ou 4 essais (2), d'une durée de $30 \mathrm{j}$. Par ligne, les valeurs surmontées en exposant de lettres identiques ne sont pas significativement différentes au seuil des $5 \%$. "PMF: poids de matière fraîche.

\begin{tabular}{lccccc}
\hline & Super & Grosso & Abrial & Aspic & Maillette \\
\hline 1 Taux de multiplication & $1,38^{\mathrm{ab}}$ & $1,68^{\mathrm{bc}}$ & $1,93^{\mathrm{c}}$ & $1,04^{\mathrm{a}}$ & $1,35^{\mathrm{ab}}$ \\
Longueur pousse principale (mm) & $22,7^{\mathrm{b}}$ & $22,0^{\mathrm{b}}$ & $27,9^{\mathrm{b}}$ & $35,7^{\mathrm{c}}$ & $10,1^{\mathrm{a}}$ \\
PMF* $(\mathrm{mg})^{\text {Viabilité (\%) }}$ & $87,8^{\mathrm{a}}$ & $88,3^{\mathrm{a}}$ & $187,3^{\mathrm{b}}$ & $63,3^{\mathrm{a}}$ & $84,9^{\mathrm{a}}$ \\
Vitrification (\%) & 70,9 & 67,2 & 88,5 & 69,7 & 56,9 \\
2 Enracinement (\%) & 2,7 & 5,2 & 4,2 & 5,0 & 3,0 \\
Longueur pousse principale (mm) & 5,9 & 0,0 & 1,0 & 0,0 & 2,1 \\
Nombre de racines & $27,5^{\mathrm{b}}$ & $23,9^{\mathrm{b}}$ & $29,9^{\mathrm{b}}$ & $31,4^{\mathrm{b}}$ & $10,2^{\mathrm{a}}$ \\
Longueur racine la plus longue (mm) & $5,1^{\mathrm{b}}$ & $6,6^{\mathrm{b}}$ & $5,1^{\mathrm{b}}$ & $6,4^{\mathrm{b}}$ & $2,6^{\mathrm{a}}$ \\
Viabilité (\%) & $12,8^{\mathrm{b}}$ & $12,7^{\mathrm{b}}$ & $14,3^{\mathrm{b}}$ & $16,0^{\mathrm{b}}$ & $6,5^{\mathrm{a}}$ \\
3 Enracinement (\%) & $85,2^{\mathrm{b}}$ & $71,2^{\mathrm{b}}$ & $79,3^{\mathrm{b}}$ & $85,1^{\mathrm{b}}$ & $40,0^{\mathrm{a}}$ \\
Longueur pousse principale (mm) & $97,5^{\mathrm{b}}$ & $95,0^{\mathrm{b}}$ & $93,7^{\mathrm{b}}$ & $97,7^{\mathrm{b}}$ & $57,0^{\mathrm{a}}$ \\
\hline
\end{tabular}


Vaucluse. Par ailleurs, 20000 plants du clone Abrial ont été produits selon la méthode décrite par un laboratoire commercial, et implantés dans la Drôme.

Dans tous les cas, nous avons pu noter un pourcentage de reprise voisin de $100 \%$, une vitesse de croissance et une vigueur remarquables, et aucun cas significatif de "dépérissement » du matériel végétal.

Dans l'essai de comportement proprement dit, portant sur 1000 vitroplants du clone Grosso et 600 boutures ligneuses traditionnelles du même clone, la supériorité du développement des vitroplants apparaît clairement dans la figure 3 ; des informations complémentaires ont été obtenues sur les rendements respectifs, en matière fraîche et en huile essentielle (tableau III) et sur la composition analytique de cette dernière (tableau IV). Par rapport aux plants témoins, les rendements en huile essentielle des vitroplants sont respectivement supérieurs de 200 , 100 et $60 \%$ au cours des 3 premières années.

L'analyse des chromatogrammes des huiles essentielles, montre que la répartition des principaux composés, est comparable entre les vitroplants issus du clone Grosso et les boutures ligneuses, et se révèle conforme aux normes officielles retenues pour ce clone.

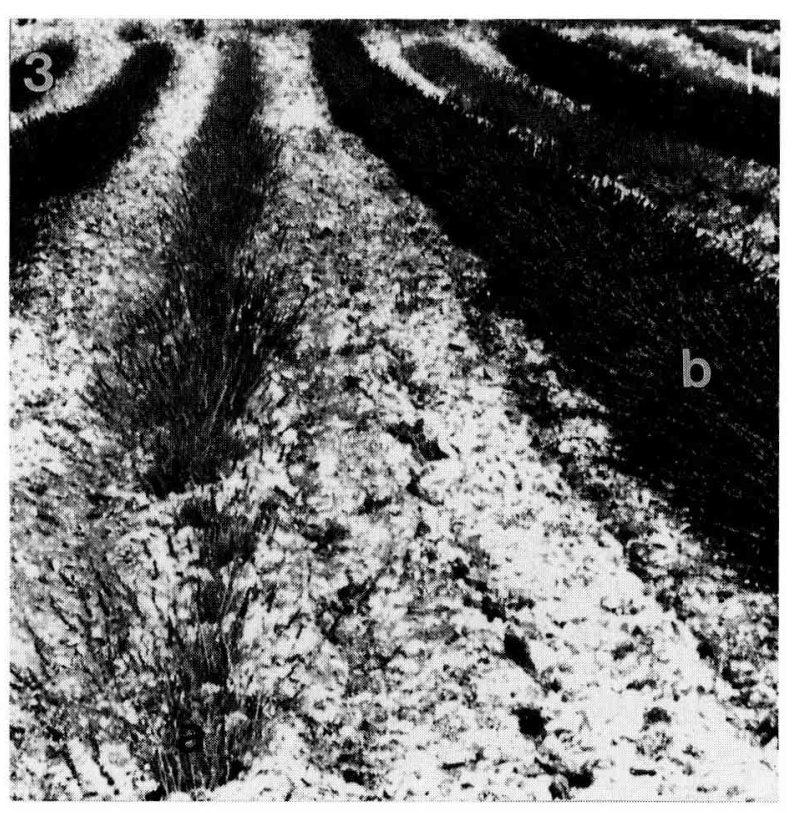

Fig 3. Comportement comparé au champ de vitroplants (b) et de boutures ligneuses (a) de lavandins Grosso âgés d'un an.
Tableau III. Comparaison des rendements en matière fraîche (MF) et en huile essentielle (HE), de vitroplants du clone Grosso et de plants traditionnels (boutures ligneuses), au cours de 3 années de culture.

\begin{tabular}{|c|c|c|c|c|c|}
\hline \multirow[b]{2}{*}{ Années } & \multicolumn{3}{|c|}{$\begin{array}{c}\text { Rendement en } M F \\
(\mathrm{~kg} / \mathrm{ha})\end{array}$} & \multicolumn{2}{|c|}{$\begin{array}{c}\text { Rendement en HE } \\
\text { (I/ha) }\end{array}$} \\
\hline & $\begin{array}{l}\text { Vitro- } \\
\text { plants }\end{array}$ & & $\begin{array}{l}\text { outures } \\
\text { neuses }\end{array}$ & $\begin{array}{l}\text { Vitro- } \\
\text { plants }\end{array}$ & $\begin{array}{l}\text { Boutures } \\
\text { ligneuses }\end{array}$ \\
\hline $1^{e r}$ & 1624 & & 503 & 34,12 & 11,07 \\
\hline $2^{e}$ & 6090 & 3 & 045 & 89,90 & 36,20 \\
\hline $3^{e}$ & 6317 & 3 & 848 & 107,39 & 73,11 \\
\hline
\end{tabular}

Tableau IV. Comparaison de la composition en huiles essentielles de vitroplants du clone Grosso et de plants traditionnels (boutures ligneuses) en $1^{\text {re }}$ année de culture.

\begin{tabular}{lccc}
\hline \multirow{2}{*}{$\begin{array}{c}\text { Composant } \\
\text { en différents composants (\%) }\end{array}$} \\
\cline { 2 - 4 } & $\begin{array}{c}\text { Vitro- } \\
\text { plants }\end{array}$ & $\begin{array}{c}\text { Boutures } \\
\text { ligneuses }\end{array}$ & $\begin{array}{c}\text { Normes } \\
\text { AFNOR }\end{array}$ \\
\hline Cinéole 1-8 & 7,20 & 5,29 & $4-7$ \\
Limonène & 0,88 & 0,77 & $<1,5$ \\
Camphre & 7,67 & 8,85 & $6-8$ \\
Linalol & 33,09 & 31,44 & $25-35$ \\
Acétate de linalyle & 26,38 & 22,42 & $28-38$ \\
Terpinène 101-4 & 3,86 & 3,85 & $2-4$ \\
Bornéol & 2,77 & 2,93 & $1,5-3$ \\
Lavandulol & 0,41 & 0,48 & $0,3-0,5$ \\
Acétate de lavandulyle & 1,90 & 2,85 & $1,5-3$ \\
\hline
\end{tabular}

\section{DISCUSSION - CONCLUSION}

Les travaux réalisés ont conduit à la maîtrise des conditions de multiplication végétative in vitro de 3 clones commerciaux de lavandins (Abrial, Super, Grosso) et d'un clone de lavande aspic; les milieux de culture et les conditions d'environnement utilisés ont permis l'entretien et l'amplification des souches correspondantes pendant près de 50 subcultures mensuelles sans dérive significative de l'état des cultures qui conservent un aspect et une structure satisfaisants.

Cependant, pour les lavandins, des différences interclonales apparaissent: l'adjonction d'une auxine (AIB), même à une concentration faible, est indispensable pour la multiplication 
du clone Abrial, alors qu'une cytokinine (N6 Benzyladénine) seule suffit pour celle des pousses des clones Super et Grosso.

Il faut noter que les milieux de culture utilisés ici apparaissent moins riches (éléments nutritifs minéraux, concentrations en régulateurs de croissance) que ceux préconisés par d'autres auteurs. Ceux-ci utilisent, pour le stade de multiplication, les formulations de Murashige et Skoog, 1962 (Quazi, 1980; Oliphant, 1987; Calvo et Segura, 1989 ou de Linsmaier et Skoog, 1965; Panizza et Tognoni, 1988; Panizza et al, 1988), apportant une concentration importante en éléments carbonés et une teneur en cytokinine au moins égale à $0,2 \mathrm{mg} / \mathrm{l}$. Dans nos conditions expérimentales, l'application des combinaisons précédentes a conduit après 3 subcultures, à des souches présentant des symptômes généralisés de «vitrification », inutilisables pour une multiplication ultérieure.

Dans le cas du milieu d'enracinement, l'adjonction d'acide indolacétique à la concentration de $0,4 \mathrm{mg} / \mathrm{l}$ s'est également révélée plus favorable que l'apport d'acide indolbutyrique (Oliphant, 1987) ou d'acide naphtalène acétique (Panizza et Tognoni, 1988; Panizza et al, 1988) à une concentration plus élevée (1 mg/l): l'usage de ces derniers régulateurs induit fréquemment, dans les clones étudiés, la formation d'un cal basal et la nécrose d'un certain nombre de bourgeons apicaux, ce qui pourrait indiquer un excès d'auxine exogène.

Le milieu unique d'enracinement défini ici convient bien aux 3 clones de lavandins: il assure, en un temps bref, l'émission de plusieurs racines ramifiées, l'élongation ultérieure de l'axe caulinaire et la préparation satisfaisante des individus aux conditions de culture ex vitro.

Les comportements des clones parentaux de lavande aspic et Maillette, apparaissent très contrastés:

- dans le cas de la lavande aspic, l'utilisation d'un milieu de propagation par bourgeonnement axillaire conduit à un taux de multiplication réduit, voisin de 1. En revanche, compte tenu de l'aptitude élevée à l'enracinement de ce clone, la multiplication des souches par bouturage semble préférable;

- le comportement de la lavande Maillette est plus marginal: la combinaison milieu de culture-condition d'environnement utilisé ici n'a permis l'entretien des souches que pen- dant un nombre limité de subcultures et a conduit à la nécrose des explants.

Ces différents résultats indiquent que la mise en œuvre d'une méthodologie unique de micropropagation dans le groupe lavandes-lavandins est exclue: pour chaque clone nouveau, il conviendra de définir la meilleure combinaison milieu de culture-condition d'environnement. À ce titre, la diversification des paramètres - température et intensité d'éclairement - devra être étudiée, compte tenu d'une adaptation plus ou moins bonne des clones aux diverses zones de plantation. L'exemple de l'échec observé pour la lavande Maillette pourrait être partiellement imputable à des conditions d'environnement défavorables et des recherches complémentaires sont actuellement en cours, pour définir une méthodologie efficace applicable aux lavandes fines.

Sur le plan agronomique, une part importante et originale de notre travail a consisté en la production puis l'observation d'un nombre important d'individus, jusqu'au stade d'exploitation industrielle du matériel végétal. La conformité des plants obtenus in vitro a ainsi été authentifiée par l'étude des performances au champ de 45000 lavandins, tous clones confondus.

Après 3 années d'observations, les plants de tous les clones manifestent une vitesse de croissance et une vigueur remarquables sans manifestation de symptômes de "dépérissement ". Dans le cas du clone Grosso, ils démontrent en outre une bonne productivité, indiquée par un rendement précoce et élevé en huile essentielle dont la composition atteste la conformité au type parental. Ces observations, constituent donc une base fiable quant au jugement de la valeur du matériel végétal issu de culture in vitro, mais 2 réserves doivent être apportées à ces résultats: - des séries complémentaires d'analyses chimiques devraient être réalisées pour confirmer ces données préliminaires,

- la longévité habituelle moyenne des cultures étant de l'ordre de 10 ans, les observations devront être poursuivies pendant au moins cette durée, afin de mesurer la pérennité éventuelle du gain de performances, observé à ce jour.

En conclusion la méthodologie proposée paraît bien adaptée à la multiplication rapide des clones de lavandins étudiés et permet l'obtention de plants d'une qualité agronomi- 
que satisfaisante. Si une production directe et massive de vitroplants peut paraitre poser un problème de coût économique, en revanche la méthode décrite est sans doute parfaitement applicable à la constitution de lots de pieds mères producteurs de boutures présentant un excellent état sanitaire. Ce dernier facteur n'est pas négligeable si l'hypothèse de la responsabilité d'agents pathogènes connus ou nouveaux dans le syndrôme de " dépérissement» était confirmée.

\section{REMERCIEMENTS}

Nous tenons à remercier J Onilion pour sa précieuse collaboration en statistiques, C Huet pour sa participation technique et $P$ Venard pour ses clichés photographiques.

\section{RÉFÉRENCES}

Anonyme (1989), Recueil de normes françaises AFNOR Huiles Essentielles, AFNOR, $3^{e}$ édn

Caire G (1970) Enquête sur la culture et le dépérissement du lavandin. Rapport de stage, majseptembre 1970. ENITA de Bordeaux. Stn Agron, INRA Antibes

Calvo MC, Segura J (1988) In vitro morphogenesis from explants Lavandula latifolia and Lavandula stoechas seedlings. Sci Hortic, 36, 131-137

Calvo MC, Segura J (1989) In vitro propagation of Lavender. Hortscience 24, 375-376

Chailan C (1989) Production et marché des essences de lavande et de lavandin. Communication au cours des $\mathrm{J}$ Tech lavandes-lavandins. Montbrun-Les-Bains, 14 oct 1989

Chambon C, Poupet A, Beck D (1987) Capacités d'organogenèse in vitro de quelques espèces aromatiques, médicinales et à parfum. Applica- tion à la multiplication végétative. Actes des $6^{\mathrm{e}}$ $\mathrm{J}$ Int Huiles essentielles, Digne-Les-Bains, 3-4-5 sept, 1987

Chambon C, Maia N, Poupet A (1988) Perspectives d'application de certaines biotechnologies à la famille des Labiées. Actes des $7^{\mathrm{e}} \mathrm{J}$, Huiles Essentielles. Digne-Les-Bains, 1-2-3 septembre 1988

Cousin MT, Gourret JP, Lacoste JP, Leclant F (1969) Découverte de particules de type «mycoplasme "dans le liber de Convolvulus arvensis récoltés dans un champ de lavandins atteints de flétrissements. Ann Phytopathol 1 , 297-300

Linsmaier EM, Skoog F (1965) Organic growth factor requirements of tobacco tissue culture. Physiol Plant, 18, 100-106

Maia E, Bettachini B, Beck D, Venard P, Maia N (1973) Contribution à l'amélioration de l'état sanitaire du Lavandin, clone Abrial, Ann Phytophathol 5, 115-124

Maia N, Beck D, Marais A, Poupet A, Venard P (1981) La sélection du lavandin. Riv Italiana EP. POS-LXIII, 163-167

Murashige $T$, Skoog $F$ (1962) A revised medium for rapid growth and bioassays with tobacco tissue cultures. Physiol Plant 15, 473-497

Oliphant JL (1987) Micropropagation of Lavandula species $\mathrm{In}$ : The International plant propagators society. Comb Proc 37, 158-160

Panizza M, Tognoni F (1988) Clonal propagation, callus formation and plant regeneration of Lavandin. Sci Hortic 37, 157-163

Panizza M, Mensuali Sodi A, Tognoni F (1988) In vitro propagation of Lavandin: ethylene production during plant development. Acta Hortic 227, 334-339

Quazi MH (1980) In vitro multiplication of Lavandula spp, Ann Bot 45, 361-362

Tulecke W, Sehgal N (1963) Cell proliferation from the pollen of Torreya nucifera. Contrib Boyce Thomson Inst 22, 153-163

Webb JK, Banthorpe DV, Watson DG (1984) Monoterpene synthesis in shoots regenerated from callus cultures. Phytochemistry, 23, 903-904 